\title{
Cystitis Cystica
}

National Cancer Institute

\section{Source}

National Cancer Institute. Cystitis Cystica. NCI Thesaurus. Code C96230.

A reactive inflammatory disorder affecting the bladder. It is characterized by the development of small cysts in the bladder wall. The cysts are lined by urothelial cells. 